\title{
Technology Use, Training and Plant-Specific Knowledge in Manufacturing Establishments
}

\author{
by John R. Baldwin*, Tara Gray** and Joanne Johnson*** \\ Micro-Economics Analysis Division, Statistics Canada
}

No. 86

\begin{abstract}
11F0019MPE No. 86
ISBN: 0-660-15592-3

ISSN: 1200-5223
\end{abstract}

24B, R.H. Coats Building, Ottawa, K1A 0T6

Facsimile Number: (613) 951-5403

* Phone: (613) 951-8588

$* *(613) 951-5314$

$* * *(613) 951-3547$

Email: BALDJOH@STATCAN.CA

December 1995

This paper represents the views of the authors and does not necessarily reflect the opinions of Statistics Canada. 


\section{ANALYTICAL STUDIES BRANCH RESEARCH PAPER SERIES}

The Analytical Studies Branch Research Paper Series provides for the circulation, on a prepublication basis, of research conducted by Branch staff, visiting Fellows and academic associates. The Research Paper Series is intended to stimulate discussion on a variety of topics including labour, business firm dynamics, pensions, agriculture, mortality, language, immigration, statistical computing and simulation. Readers of the series are encouraged to contact the authors with comments, criticisms and suggestions. A list of titles appears inside the back cover of this paper.

Papers in the series are distributed to Statistics Canada Regional Offices, provincial statistical focal points, research institutes, and specialty libraries.

To obtain a collection of abstracts of the papers in the series and/or copies of individual papers (in French or English), please contact:

Publications Review Committee

Analytical Studies Branch, Statistics Canada

24th Floor, R.H. Coats Building

Ottawa, Ontario, K1A 0T6

(613) 951-1804 


\section{Abstract}

This study examines the factors influencing a firm's decision to train, using data taken from several recent Statistic Canada surveys that explore advanced technology use by Canadian manufacturing plants. Advanced technology adoption has been both rapid and pervasive, leading to concerns about whether technology use is associated with an increase or a decrease in workers' skills. Based on the data collected through two surveys, this paper examines the relationship between technology use and the skill level of workers. It does so by first reporting on the opinions of managers of Canadian manufacturing establishments, who indicate that technology use leads to skill increases. Second, this paper examines the relationship between a plant's decision to train and certain other characteristics of the plant, including its technology use. Third, it investigates the factors related to the location of training in order to determine whether the training done by plants imparts primarily generic skills or plant-specific skills. Finally, it reports on survey results that show plants that introduced new technologies had to increase their expenditures for training.

Keywords: technology; incidence of training; skill requirements; costs of training; specific versus generic skills. 



\section{Executive Summary}

Recent technological advances have fostered a concern regarding the impact of technology on workers. This paper investigates the extent of technology use in Canadian manufacturing establishments and the degree to which it leads to greater investment in human capital.

\section{Advanced technology use by Canadian manufacturing establishments is widespread and growing}

Advanced technology use in the Canadian manufacturing sector has transformed the nature of production, transportation, and communication systems and, consequently, the nature of work and workers. This is evidenced by the widespread proliferation of advanced manufacturing technologies (AMTs). Approximately 92 percent of Canadian manufacturing shipments were produced in establishments using advanced computer-based manufacturing technologies in 1993. Growth in the use of AMTs over the last few years has been dramatic, rising from 23 percent of shipments in plants using 10 or more technologies in 1989 to 38 percent in 1993. While this growth is attributable in part to new users, most of the expansion is due to an increase in the number of technologies in use. By 1993, multiple technology use was prevalent-in 1993, only 5 percent of shipments were produced by single-technology users compared to 69 percent for establishments using at least 5 technologies.

\section{Advanced technology use leads to increases in the skill levels of workers}

The impact of advanced technology use on workers has been the subject of considerable debate. This debate focuses on whether technology adoption brings about an increase or a decrease in the required skill level of workers. Based on the data collected through the two surveys, this analysis associates technology use with an increase in the required skill level of workers.

The most direct evidence is provided by the 1993 Survey of Innovation and Advanced Technology, where plant managers were asked if the introduction of advanced technologies increased, more often than reduced, the skill requirements of workers. The percentage of plants experiencing an increase is four to five times larger than those experiencing a decrease.

\section{Investments in human capital are complementary to investments in advanced technologies}

A consequence of advanced technology adoption is the need for a more highly educated, adaptable, and skilled workforce. This need for skilled workers can be met in two ways-either through the hiring of new personnel or through the training of existing employees. Training will be a firm's response when the skills it needs are highly sophisticated and/or plant-specific, as is the case for firms using AMTs. 
Data from the 1989 Survey of Manufacturing Technologies provide a clear link between an increase in the incidence of training and an increase in the number of technologies in use. The use of just one advanced manufacturing technology increases the incidence of formal training from 77 percent to 90 percent of manufacturing plants (establishment-weighted); virtually all manufacturing plants using five or more technologies engage in formal training.

Training is just one of the many strategies that firms can adopt in their pursuit of success. The degree to which a firm will find benefit from training is determined by the competencies the firm possesses and the other strategies it pursues. Therefore, the intensity of training is related here via multivariate analysis to the firm's activities and characteristics, including its use of AMTs.

\section{Advanced technology-using firms are more likely to train}

Regression analysis confirms that training is an important part of the technology strategy pursued by firms. Advanced technology use is one of the most important determinants of whether or not a plant will train its workers; the probability of training taking place increases as the number of technologies in use increases. Furthermore, plants experiencing difficulties in hiring skilled workers to work with AMTs are also more likely to engage in training.

\section{Training is an important element of the strategies pursued by successful firms}

Regression analysis also indicates that training is an integral part of the overall strategy of successful firms. Firms engaging in R\&D and operating in an innovative industry, both indictors of management's ability to learn and adapt, are more likely to engage in training. Growing and/or older firms, characteristics associated with a firm's past success, are also positively associated with training.

\section{The location of training is indicative of the nature of the skills being imparted by training}

Training can be aimed at upgrading or creating two types of skills. The first is tacit, or plantspecific knowledge, which allows workers to make things work within a specific environment. Consequently, training for these plant-specific skills is likely to take place on the plant floor. The second type is sophisticated generic knowledge. Training for sophisticated generic skills is more likely to take place off the plant floor, either elsewhere in the firm, or through the purchase of training courses.

Training for generic skills suffers from an externality problem; once gained, they are more easily transferred across firms than are plant-specific skills. Consequently, investments in generic worker skills are inherently riskier than those in plant-specific skills. Thus, training for these skills may not be offered in optimum quantities by firms. 
The type of training is influenced by both the number and type of technologies used by a firm.

The location of training then is related to the basic nature of the training being imparted. The characteristics and activities associated with location depend on which of the two skill types are dominant, whether training is aimed primarily at specific or non-specific skills. Regression analysis indicates that use of more AMTs leads to training taking place primarily off the plant floor. The use of certain types of AMTs leads to either training on or off the plant floor, depending on whether the technology is more generic or more plant-specific.

Leading firms have developed tacit knowledge which imparts unique needs that can only be satisfied by training on the plant floor

Training on the plant floor is more likely to take place in firms displaying characteristics of and engaging in activities associated with leading-edge firms. Generally, the skills required by such firms will be less generic and more plant-specific. Difficulty in hiring workers familiar with the firm's technologies increases the likelihood of training taking place on the plant floor, as the knowledge required here is very plant specific. Firms that modify, rather than just use existing technology, that engage in $\mathrm{R} \& \mathrm{D}$, and that are diversified and/or mature, are all more likely to have a need for plant-specific skills and, thus, are more likely to train on the plant floor.

\section{Technology adoption leads to greater investment expenditures in human capital}

Technology adoption has resulted in more investment in human capital, as measured by higher training costs. Firms were asked in the 1993 Survey of Innovation and Advanced Technology to assess the impact that the adoption of technology had on their education and training costs. The responses confirm the results of the regression analysis-training resulting from technology adoption does not simply replace other training done by the firm, it creates a need for more training than was previously done by the firm. Between two-thirds and three quarters of technology-using plants (shipment-weighted) reported that the adoption of technology increased their education and training costs, depending on the functional technology group (i.e., design and engineering, fabrication and assembly, inspection and communications, material handling systems) being used.

The effects of advanced technology use on training is felt more by larger firms than by smaller firms

This paper employs two different weighting procedures; together, they offer an insight into the differences between small and large establishments with regards to training and technology use. Establishment-weighted results present a profile of the average manufacturing plant. As most plants are small, the results are representative primarily of small establishments. Shipmentweighted results present a picture more representative of large establishments, as large firms account for more economic activity than small firms. Use of the two different weighting 
procedures leads to the conclusion that larger plants tend to use more technologies, to integrate more technologies from different functional groups, and to use more sophisticated technologies than small plants and thus, have greater skill and training requirements.

\section{Several sources of data were used in this analysis}

The Survey of Manufacturing Technology (1989), and the Survey of Innovation and Advanced Technology (1993) both provide data on advanced computer-based technology use and training in Canadian manufacturing plants. The Census of Manufacturers (1980 to 1989) provides data on the performance of plants, permitting evaluation of the relationship of training to technology use and success. 


\subsection{Introduction}

Technological advances have eroded physical, cultural, economic, and political borders. These advances have revolutionized the nature of production, transportation, and communication systems and, consequently, the nature of work and workers.

Technology adoption has been both rapid and pervasive in the Canadian economy. Approximately 92 percent of Canadian manufacturing shipments were produced in establishments using advanced computer-based manufacturing technologies in 1993. This represents an increase of four percentage points over the preceding four years. Moreover, the percentage of shipments in plants utilizing ten or more technologies grew by a dramatic 15 percentage points over the same period, from 23 to 38 percent of shipments (Baldwin and Sabourin, 1995).

The explosion in technology use has fostered a concern about its impact on workers (see Betcherman, et al., 1994, for a summary of these studies). A growing debate has emerged centering on whether technology adoption increases or decreases workers' skills, the so-called "upskilling-deskilling" debate. Some have argued that new technologies permit segmentation of tasks into repetitive, mundane, skill-lacking tasks (Keefe, 1991). Others have argued that new technologies permit automation of mechanical tasks, enabling workers to devote their time to more complicated tasks, tasks that require combinations of judgment, dexterity, and experience, which cannot be programmed into computers (Bylinsky, 1994).

This paper addresses this debate by focusing on the link between the training done by a firm and its technology strategy. Training will be associated with technology adoption if the resulting changes in skill requirements necessitate either hiring appropriately skilled employees or training existing employees. The more specific to the individual firm are the increased skill requirements, the more likely it will be to turn to training, since these types of skills can only be taught or acquired within the firm.

In addition to the use of advanced technologies, many other factors will influence a firm's decision to train. Whether a firm finds training a relevant and useful activity depends on the other strategies and activities it pursues, as well as its ability to gain and assimilate knowledge imparted by training activities. Furthermore, these factors will affect the location of trainingwhether training is done either on or off the plant floor.

Two issues that originate from debate over the nature of the relationship between skills and advanced technology use are addressed in this paper. The first is the extent to which human capitalthe skills embodied within a firm's employees-is complimentary to the investments the firm makes in advanced technologies. This issue is examined by looking at the relationship between the use of technology and each of the change in skill requirements, training, and training investments.

The second issue investigated is the degree to which technology use generates a demand for either firm-specific or sophisticated generic skills. Firm-specific skills are those which firms are more 
likely to provide in socially optimal quantities without resorting to government subsidies since most of the benefits of those skills accrue directly to the firm. ${ }^{1}$ Conversely, firms may refrain from investing in sophisticated generic skills, as these skills are easily transferable across firms and are thus subject to an externality problem. Consequently, it is crucial to investigate the type of skills imparted by the training undertaken by advanced technology-using firms.

This paper begins by describing the sources of data utilized in this analysis. The next section examines the extent of technology use in Canada and reviews the technology-skill controversy. The remainder of the paper is devoted to examining the relationship between training and other factors, particularly technology, through the use of multivariate analysis. The factors influencing the incidence of training are examined first, succeeded by an analysis of the factors influencing the location of training. The final section examines evidence on the perceived direct impact of technology adoption on training costs.

\subsection{Sources of Data}

This paper draws on data from three Statistics Canada surveys - the Survey of Innovation and Advanced Technology, the Survey of Manufacturing Technology, and the Census of Manufacturers.

\subsection{The Survey of Innovation and Advanced Technology}

The first survey used here, the Survey of Innovation and Advanced Technology, was conducted by Statistics Canada in 1993 using manufacturing plants and firms of all sizes. There were five sections on the questionnaire: section 1 contained general questions, section 2 - R\&D questions, section 3 - innovation questions, section 4 - intellectual property questions and section 5 technology questions. This paper focuses on the results from section 5 , in which plants were asked to indicate their use, planned use, or non-use of 22 manufacturing technologies. Additionally, plants were queried on the benefits associated with, and the factors impeding, the adoption of these technologies, including the lack of skilled workers and the need for training. The response rate for the survey was 85.5 percent.

\subsection{The Survey of Manufacturing Technology}

The Survey of Manufacturing Technology, conducted by Statistics Canada in March 1989, is also used in this analysis. In this survey, establishments in the manufacturing sector were asked to indicate their use, planned use, or non-use of 22 separate advanced technologies (the same technologies as in the 1993 Survey of Innovation and Advanced Technology above). In addition, the survey collected data on several related characteristics of the establishment-whether or not it engaged in research and development, or had undertaken any formal training, and whether this training took place primarily within the plant or elsewhere. The survey was based on a

1 See OECD (1991), p. 136 for a discussion of the differences between a firm's incentive to invest in firm-specific as opposed to general training. 
representative sample of establishments in the Canadian manufacturing sector. There were 4200 establishments in the sample, of which 3952, or 94 percent, responded.

\subsection{The Census of Manufacturers}

In order to evaluate the performance of establishments according to their use of manufacturing technologies, plants' responses on the 1989 Survey of Manufacturing Technology are linked to longitudinal panel data on establishments going back to 1980, taken from the Census of Manufacturers. This source yields information on a plant's employment, shipments, and wages. In addition, data on the plant's owning enterprise-nationality, size, diversification, and age-are generated from special files maintained by the Micro-Economics Studies and Analysis Division.

\subsection{Weighting}

Because sampling proportions differ across industry, region and plant size in each of the surveys, the answers of the sample need to be weighted to represent the different underlying populations. Two different sets of weights are used in this analysis. Use of the first, establishment-weights, causes each establishment in the sample to represent a group of similar (with the same size, and in the same industry and region) Canadian manufacturing establishments. Establishmentweighted results present a profile of the average manufacturing establishment; as most manufacturing establishments are small, the establishment-weighted results represent primarily small establishments. The second weighting procedure, shipment-weights, takes into account the fact that different establishments account for different proportions of economic activity. In this case, the weights attached to plants are the shipment values of both their own establishment and similar establishments. As large establishments account for a larger proportion of economic activity than small establishments, shipment-weighted results present a picture that is more representative of larger establishments, and of manufacturing activity in Canada as a whole.

\subsection{Technology and Skill}

\subsection{Defining Advanced Technologies and Advanced Technology Use}

Advanced manufacturing technologies involve the application of computers to various facets of the production process. The 22 manufacturing technologies are grouped into six functional categories, each capturing a different aspect of the process-fabrication and assembly, automated materials handling systems, design and engineering, inspection and communications, manufacturing information systems, or integration and control. Table 3.1 presents the technologies and groups used in both the 1989 Survey of Manufacturing Technology and the 1993 Survey of Innovation and Advanced Technology. 
Table 3.1

Advanced Manufacturing Technologies by Functional Group

\begin{tabular}{|c|c|}
\hline Functional Group & Technology \\
\hline \multirow[t]{6}{*}{ Fabrication and Assembly } & Flexible manufacturing cells/systems (FMC/FMS) \\
\hline & Numerically Controlled (NC) Machines \\
\hline & Computer Numerically Controlled (CNC) Machines \\
\hline & Materials Working Lasers \\
\hline & Pick \& Place Robots \\
\hline & Other Robots \\
\hline \multirow[t]{2}{*}{ Automated Materials Handling Systems } & Automated Storage/Retrieval Systems (AR/RS) \\
\hline & Automated Guided Vehicle Systems (AGVS) \\
\hline \multirow[t]{3}{*}{ Design and Engineering } & Computer-aided design and engineering (CAD/CAE) \\
\hline & CAD output to control manufacturing machines (CAD/CAM) \\
\hline & Digital representation of CAD output \\
\hline \multirow[t]{7}{*}{ Inspection and Communications } & Automatic Inspection Equipment - Inputs \\
\hline & Automatic Inspection Equipment - Final Products \\
\hline & Local Area Network for Technical Data \\
\hline & Local Area Network for Factory Use \\
\hline & Inter-Company Computer Network (ICCN) \\
\hline & Programmable Controllers \\
\hline & Computers used for control in factories \\
\hline \multirow[t]{2}{*}{ Manufacturing Information Systems } & Materials Requirement Planning (MRP) \\
\hline & Manufacturing Resource Planning (MRP II) \\
\hline \multirow[t]{3}{*}{ Integration and Control } & Computer Integrated Manufacturing (CIM) \\
\hline & Supervisory Control \& Data Acquisition (SCADA) \\
\hline & Artificial Intelligence/Expert Systems (AI) \\
\hline
\end{tabular}

This paper employs two different measures of advanced technology use, capturing both the incidence and the pattern of use. Incidence of use is measured by the number of advanced technologies in use across all functional groups. Measures of advanced technology use by functional group are used to examine the pattern of use, whether some functional groups (i.e., design and engineering versus fabrication and assembly) are being utilized more heavily than others.

\subsection{Extent and Pattern of Technology Use in Canada}

Advanced technologies are used extensively in the Canadian manufacturing sector. In 1993, some 60 percent of establishments, accounting for 92 percent of shipments, used at least one of the advanced manufacturing technologies (see Table 3.2). Moreover, multiple technology use was the norm. A mere 5 percent of shipments were produced by single-technology users compared to 69 percent for establishments using at least 5 technologies.

Since the shipment-weighted incidence rate of technology use is higher than the establishmentweighted rate, larger establishments have a greater probability than smaller establishments of adopting any one of the advanced technologies. By the same reasoning, they are more likely to adopt 5 or more technologies. 
Table 3.2

Adoption Rate by Number of Technologies

\begin{tabular}{lcccc}
\hline & \multicolumn{3}{c}{ Adoption Rate } \\
\cline { 2 - 5 } Number of & percentage of establishments & 1989 & 1993 \\
Technologies & 1989 & 40 & 12 & 8 \\
\hline 0 & 52 & 14 & 5 & 5 \\
1 & 12 & 24 & 26 & 19 \\
2 to 4 & 22 & 17 & 33 & 31 \\
5 to 9 & 11 & 5 & 23 & 38 \\
10 or more & 3 & 60 & 88 & 92 \\
At least 1 & 48 & & \\
\hline
\end{tabular}

Source: Survey of Manufacturing Technology (1989) and the Survey of Innovation and Advanced Technology (1993)

Note: The 1993 numbers have been modified so that their calculation is comparable to those from 1989.

The rate of technology use increased dramatically from 1989 to 1993 . Over this period, the (shipment-weighted) percentage of plants not using any of the 22 technologies declined from 12 percent to eight percent, while the percentage of shipments in plants using 10 or more technologies increased from 23 percent to 38 percent. While some of the increase in technology use is attributed to new users (only eight percent of shipments in 1993 came from plants not using any technologies, compared to 12 percent in the earlier period), most is due to plants increasing the number of technologies they used between 1989 and 1993. Moreover, this increase occurs particularly in larger establishments, since the increase in the shipment-weighted use of 10 or more technologies (15 percentage points) is so much greater than the increase in the establishment-weighted share (2 percentage points).

While advanced manufacturing technologies have come to affect most output, their use varies considerably across functional groups. Some 73 percent of shipments in 1993 came from establishments using technologies from the inspection and communications group. The high adoption rate attributed to this particular group of technologies is due mainly to the use of automatic control devices-programmable controllers and stand-alone computers used for control on the factory floor-a sub-group of the inspection and communications class, whose shipmentweighted adoption rate was 58 percent in 1993. The inspection and communications group is followed by design and engineering (63\%), manufacturing information systems (53\%), and fabrication and assembly (46\%). Integration and control technologies were adopted by 42 percent of plants, while automated materials handling systems were adopted by just 16 percent.

Establishment-weighted technology use by functional group is considerably less, although it generally follows the same pattern of use. Design and engineering was reported as being the most widely used functional group (24\%), followed by the inspections and communications group (19\%). The differences between establishment- and shipment-weighted incidence rates indicate large establishments use relatively more advanced technologies than small establishments; weighting by shipment value gives more weight to these larger establishments. The difference between large and small plants (as reflected by the difference between the establishment- and shipment-weighted estimates) is largest for inspection and communications technologies. 
Table 3.3

Functional Technology Use, 1993

\begin{tabular}{lcc}
\hline Technology Group & $\begin{array}{c}\text { Use } \\
\text { (percentage of establishments) }\end{array}$ & $\begin{array}{c}\text { Use } \\
\text { (percentage of shipments) }\end{array}$ \\
\hline & establishment-weighted & $\begin{array}{c}\text { shipment-weighted } \\
\text { Design \& Engineering }\end{array}$ \\
Fabrication \& Assembly & 24 & 63 \\
Automated Materials Handling Systems & 16 & 46 \\
Inspection \& Communications & 3 & 16 \\
Manufacturing Information Systems & 19 & 73 \\
Integration and Control & 11 & 53 \\
\hline
\end{tabular}

Note: The 1993 numbers have been modified so that their calculation is comparable to those from 1989.

Source: The Survey of Innovation and Advanced Technology (1993)

The incidence of technology use grew in all but one of the six functional groups (see figure 3.1). The growth in shipment-weighted use was most dramatic in the design and engineering, manufacturing information systems, and integration and control functional groups. Growth in use, however, was weak in fabrication and assembly, as well as in automated materials handling systems.

Figure 3.1

Growth in Technology Use, 1989 - 1993, Shipment-weighted

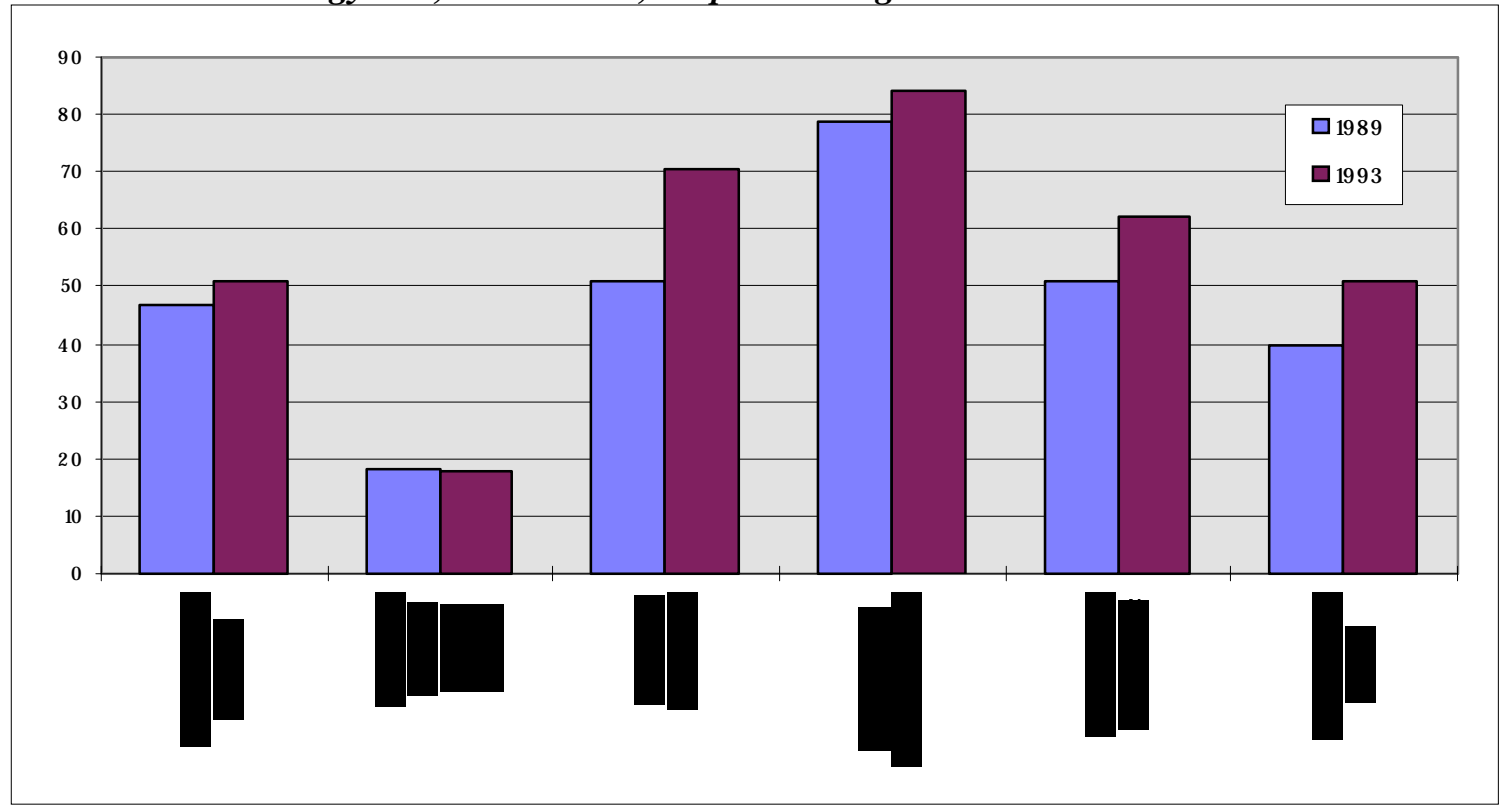

Note: The 1993 numbers have been modified so that their calculation is comparable with those from the 1989 survey.

Source: The Survey of Manufacturing Technology (1989) and the Survey of Innovation and Advanced Technology (1993)

\subsection{The Technology - Skill Controversy}

As firms adopt new advanced manufacturing technologies, their skill requirements change. What these changes entail for workers, however, has been a subject of controversy. On the one hand, the introduction of new technology has been equated with a large scale deskilling of the workforce. Proponents of this view argue that technology is used as a substitute for skilled 
workers and is responsible for lowering the average skill level of the workforce. Technology adoption, through automation, is said to result in an overall loss in conceptual tasks and control on the part of the worker (Keefe, 1991).

On the other hand, technology adoption has been associated with increases in skill levels. The introduction of technology leads to more flexible forms of production which, it is argued, can only be achieved through a highly skilled workforce (Matzner, Schettkat and Wager, 1990). Technology adoption increases the demand for skilled workers by increasing the demand for conceptual skills. Greater autonomy is given to workers. The adoption of new technologies results in a workforce that is more skilled and less subject to drudgery. Training, preparation and learning emerge as core elements of newly created work (Keefe, 1991).

There are two reasons to believe that a positive technology-skill relationship exists within the Canadian manufacturing sector. First, the pattern of technology adoption by Canadian manufacturers, discussed in section 3.2, suggests firms are increasingly turning towards "soft manufacturing", which creates a demand for skilled workers. Communications and inspection technologies are used extensively and are growing in use most rapidly. These technologies are at the heart of soft manufacturing - a manufacturing environment where software and computer networks are more important than production machines (Bylinsky, 1994). In soft manufacturing, firms use advanced manufacturing technologies to tailor their products to buyers' needs, while both improving the speed of delivery and achieving economies of scale. Workers are able to pass off repetitive or dangerous tasks and concentrate on problem solving and improving the quality of their products and services.

Second, the Survey of Innovation and Advanced Technology (1993) provides direct evidence of a positive technology-skill relationship. In this survey, plants using technologies from each of the four functional groups were asked if the introduction of that technology resulted in increased or reduced skill requirements. The results are unambiguous: plant managers observe that the introduction of the technology increases their skill requirements more often than it reduces them. The establishment- and shipment-weighted percentage of plants using a technology that experienced skill increases as opposed to decreases, are presented in Table 3.4. The percentage of plants experiencing an increase is four to five times larger than those experiencing a decrease. Plants accounting for 47 to 59 percent of shipments indicated that skill requirements increased, while only 5 to 16 percent of shipments were in plants experiencing a skill decline. ${ }^{2}$

The percentage of plants indicating that skill requirements increased is greater for the shipmentweighted averages than for the establishment-weighted calculations. Thus, it is the larger plants that experience the greatest increases in skill requirements associated with technology acquisition. There are a number of reasons for this. Large plants tend to use more advanced technologies per plant. They tend to combine technologies across functional groups more often.

2 Skill impacts are often seen differently at different levels within the plant. It has been suggested to the authors that in some cases, plant managers and other senior management may not be in a position to adequately judge the micro-skill effects of technology adoption. However, plant managers' opinions on the effects of technology adoption are corroborated here by data on the costs of training - the adoption of advanced technology has also led to a general increase in the costs of training (See section 6.0). This suggests that either more training was being offered or that the training being offered was more sophisticated. Either would lead to an overall increase in skill levels. 
They are more likely to employ the most sophisticated integration and control technologies. Large plants also tend to be greater users of the leading edge technologies within in each functional group (Baldwin and Sabourin, 1995).

Table 3.4

Impact of Technology Adoption on Skill Requirements

\begin{tabular}{|c|c|c|c|c|}
\hline \multirow[b]{2}{*}{ Technology } & \multicolumn{4}{|c|}{ Impact on skill requirements } \\
\hline & Increased & Reduced & Increased & Reduced \\
\hline & \multicolumn{2}{|c|}{ shipment-weighted } & \multicolumn{2}{|c|}{ establishment-weighted } \\
\hline Fabrication and Assembly & 56 & 16 & 23 & 9 \\
\hline Automated Materials Handling Systems & 59 & 5 & 7 & 3 \\
\hline Design and Engineering & 54 & 8 & 27 & 5 \\
\hline Inspection and Communications & 47 & 6 & 15 & 2 \\
\hline
\end{tabular}

Source: The Survey of Innovation and Advanced Technology (1993)

\subsection{Technology and Training}

\subsection{A Model of Training}

If technology is skill enhancing, producers would be expected to improve the skill sets of their workforces by hiring more highly skilled workers and by providing more training. The latter is true especially if the skills are firm-specific and, thus, require development within the firm. This section seeks to corroborate the evidence arising from plant managers' own evaluations that human capital requirements are enhanced in technologically advanced firms, by examining the relationship between the incidence of training across plants and the use of advanced technologies.

The managers of manufacturing plants indicate that intensity of technology use and intensity of training are highly related. The incidence of formal training increases as the number of technologies in use increases (Table 4.1). The use of just one advanced manufacturing technology increases the incidence of formal training from 77 percent to 90 percent of manufacturing plants (establishment-weighted); virtually all manufacturing plants using five or more technologies engage in formal training.

Table 4.1

Incidence of Formal Training by Technology Use, 1989 (Establishment-weighted)

\begin{tabular}{lcccc}
\hline & \multicolumn{4}{c}{$\begin{array}{c}\text { Number of technologies in use } \\
\text { (percent of establishments) }\end{array}$} \\
\cline { 2 - 4 } & 0 & 1 & 2 to 5 & 5 or more \\
\hline & & & & 1 \\
No training provided & 23 & 10 & 7 & 99 \\
Training provided & 77 & 90 & 93 & 1 \\
\hline
\end{tabular}

Source: The Survey of Manufacturing Technology (1989) 
It is, however, important to recognize that training is just one of the many decisions that a firm must make. Therefore, the relationship between training and technology use needs to be examined within the context of a plant or firm's other activities and strategies, through the use of multivariate analysis.

The success of a firm depends critically upon two factors-its inherent abilities and the strategies it chooses to adopt. Strategies encompass the overall organization plan adopted to meet the firm's goals. Strategies involve decisions about technology, quality control, financing, the product-delivery plan, and the inputs to be employed. The effectiveness of these strategies in turn depends upon the competencies that have been developed by a firm in these areas. Successful training, by improving the skill level of workers and enabling them to better adapt to innovations, is an integral part of this process. The goal of training is to improve worker productivity, which in turn improves the performance of the firm.

Training, however, is not conducted in a vacuum. It is an activity that is complementary to other activities-primarily to the innovation activities conducted by a firm (Baldwin and Johnson, 1995a). In some sectors, it provides the human capital that is complementary to the innovation capital of the firm. In some cases, this innovation capital stems from new technologically advanced equipment and/or from product and process innovations arising from research and development. In other cases, improvements in human capital are the innovation capital of the firm.

Regardless of whether advances in human capital are complimentary to, or synonymous with, innovation, the innovative strategy of a firm is expected to determine the desirability of training. Several different characteristics are used here to represent situations where an innovative strategy is more likely to be more prevalent and, therefore, where training will be more profitable. In addition, other characteristics of the plant will also determine investments in training. These characteristics are those that proxy a plant's ability to implement a successful training programits receptor capabilities. Some plants, because of their superior abilities, will be able to train at a lower cost, and therefore, will be more likely to train. Adoption is also posited to be a function of the innovative activities of the plant. ${ }^{3}$ The adoption of a particular human resource policytraining-is consequently posited to be a function of the activities and characteristics of a plant.

\subsection{Determinants of Training}

There are several ways to measure training activity. The first way is to measure the incidence of training-whether the plant has engaged in any training. Alternatively, the undertaking of a particular type of training, formal or informal, can be investigated. More detailed information on training may also be investigated, such as the number of workers trained or the amount of or expenditures devoted to training.

\footnotetext{
A firm's decision to train is also likely to be affected by the human resource strategy that the firm pursues. Baldwin and Johnson (1995b) find that the emphasis given to human resource strategies is strongly related to training. In manufacturing, the human resource strategy--including training--of the firm is dictated by its innovative stance. Consequently, the emphasis on human resources has no additional impact in explaining training.
} 
The analysis in this paper adopts the first approach. The training variable used here is a dichotomous variable that equals one if any formal training of the plant's employees has taken place, regardless of the location of that training, and zero otherwise. This binary variable covers only the decision to train and imparts no information on the intensity of training.

Incidence of training was chosen as the dependent variable for both practical and theoretical reasons. First, the 1989 Survey of Manufacturing Technology only investigated whether or not the plant engaged in formal training, and the location of the training. ${ }^{4}$ While this limits the extent to which other measures can be used, previous work that examines the determinants of training incidence using measures of both incidence and intensity of training (Baldwin and Johnson, 1995a) has shown that the decision to train is more closely related to a firm's overall strategies and activities than the intensity of training. Once the decision to train has been made, the number of workers trained depends almost solely on the numbers of workers within occupational categories in the firm, and the amount spent on training depends almost entirely on the number of workers trained. In other words, other strategies, activities and characteristics of the firm are less important in determining the intensity of training than the occupational mix-with some groups of workers having a higher propensity of training than others (Baldwin and Johnson, 1995a). ${ }^{5}$

\subsubsection{Activities}

The use of advanced manufacturing technologies is an activity associated with ongoing increases in the skill level of workers. ${ }^{6}$ Therefore, the number of advanced technologies in use is hypothesized to be positively related to the probability of training, since more intensive technology use implies more complex production processes and, hence, a need for more adaptable, skilled workers. Plants that use more advanced technologies will generally be the ones either that have to integrate technologies from different functional areas or that have machinery of greater complexity. Technology use is captured here with four zero-one binary variables, representing four categories of use-the use of no advanced technologies, one technology, two to five technologies, or five or more technologies.

The plant's research and development activities are also expected to influence the decision to train. There are several reasons for this. A plant that performs or supports R\&D is more likely to be receptive to change requiring greater adaptability from its workers. It is also more likely to be continually introducing new concepts in the form of either new products or new processes. Firms

4 In the survey questionnaire, plants were asked to indicate where most of the formal training done for the staff in the plant took place-either through the purchase of training courses or seats in public or private training institutes, within the plant, elsewhere in the firm. While informal training may also be an important means for meeting skill requirements in firms, Baldwin and Johnson (1995a) found that the relationship between formal training and various aspects of technological innovation was very similar to that between informal training and these same innovative characteristics.

It is true, however, that more innovative plants generally employ a higher percentage of professional and technical/production workers and a lower percentage of other workers relative to non-innovative plants. In turn, a greater proportion of these employees are trained (Baldwin and Johnson, 1995a). This is confirmed in this paper, where the results of the regression analysis indicate that the innovativeness of a firm or the industry in which the firm operates increases the probability of that firm offering training.

6 See Mincer (1989) and Bartel and Lichtenberg (1987) for studies of the link between technological change and human capital requirements. 
engaging in $R \& D$ also tend to have better educated workers; better educated workers are more likely to receive training (OECD, 1991). Consequently, performers of R\&D are more likely to train. This factor is captured by a variable that equals zero if no research and development is being performed for the plant and one if it is, regardless of whether that research is done within the plant, elsewhere within the firm, or contracted outside the firm.

\subsubsection{Characteristics}

The characteristic variables capture factors that make certain plants more receptive than others to training. These variables represent the degree of innovativeness, the level of foreign ownership of the plant, and its experience in hiring workers with the requisite skills. Other factors including the size, age, level of diversification, and region of operation of the plant are also included. Some of the variables are characteristics of the plant, while others are characteristics of the plant's owning enterprise.

The decision to train should be related to the availability of skilled workers. If a plant cannot fill positions through external sources, it will be more likely to engage in training. The model controls for this factor through the use of a binary hiring variable, which equals one if the plant has had difficulty in hiring skilled personnel to work with the plant's technologies and zero otherwise.

The decision to train is also hypothesized to be affected by the particular industry, or industries, in which the plant produces. Some sectors are more innovative than others. Those who produce more innovations are likely to demand continually changing skills of their employees and, thus, require training (Baldwin and Johnson, 1995a). To control for this, a binary variable that classifies the industry in which the plant is located as more innovative and less innovative is included. The classification is derived from Robson et al. (1988), who investigate differences in innovative tendencies of 2-digit industries. They find that the 2-digit industries fall into three basic groups. The first two groups, which are defined here as the innovative industries, produce the majority of innovations. Many of these innovations are used by the less innovative industries. The more innovative industries consist of electrical and electronic products, chemicals and chemical products, machinery, refined petroleum and coal, transportation equipment, rubber products, non-metallic mineral products, plastics, fabricated metals, and primary metals. The less innovative industries are textiles, paper, wood, clothing, leather, beverages, food, furniture and fixtures, and printing and publishing.

A measure of the number of industries in which an establishment's parent enterprise operates is included to capture the effects of diversification. Multi-plant enterprises have multiple contact points which permit them to develop an information advantage. The broader knowledge base in diversified firms may confer spill-over benefits for training. Alternatively, diversified firms, because of their complex management structures, may require higher levels of training at the plant level. For example, employees at the plant level in highly diversified firms may have to take greater responsibility than single industry plants to compensate for a lack of concentrated industry-specific expertise at the head office. The model controls for this effect by including a binary variable which equals one if the firm operates in more than one industry and zero if not. 
Training is a strategy that complements others and should be found in firms that have developed competencies resulting in growth. Output growth of the plant in the 1980s is included here as a proxy for recently developed competencies that are associated with success. Plants that have experienced little recent growth may be in that position because they are resistant to change; if so, they are also less likely to train. Growing plants may not only be more receptive to change, they may also have a greater necessity to train as their workers take on new functions associated with dealing with a larger, and perhaps more diversified market. In this analysis, growth is measured by a binary variable that categorizes plants based on the size of the change in shipments over the period of study. The variable equals zero if the plant experienced negative or small growth, and one if it experienced moderate or rapid growth. ${ }^{7}$

The age of the plant is another characteristic hypothesized to be related to the incidence of training. Older plants have more experience on which to draw and might be expected to have better information about where training would be most useful, as compared to younger plants. In this case, training would be part of a mature culture. On the other hand, younger plants may have newer technologies. Newer technologies may be more sophisticated and require higher skill levels. If so, workers in young plants will require more training. A binary variable is used to capture age effects-one for plants born after 1970, and zero otherwise.

Foreign ownership captures a set of competencies hypothesized to be positively correlated with a firm's decision to train. Multinationals are the vehicle through which hard-to-transfer scientific knowledge is moved from one country to another (Caves, 1982). They perform this function either because of scale economies associated with their larger size or because of an inherent advantage associated with information that is uniquely held by these firms. They might, therefore, be expected to receive more benefits from training programs. To capture the advantages of foreign-owned plants, a binary variable is included that equals one if a manufacturing plant is foreign-controlled, and zero otherwise.

Size has also been linked to training for a variety of reasons. It has been argued that large firms have access to cheaper capital to finance investment in training (Hashimoto, 1979), that large firms can reduce the risk and, therefore, the cost of investment in training by pooling risks (Gunderson, 1974), and that large firms have a greater pay-off from training because their size and their exploitation of economies of scale have led to task specialization and, thus, a greater benefit arising from training (Doeringer and Piore, 1971). Scale is also a proxy for the many competencies that lead to growth since size is directly related to cumulative success in previous periods. Alternately, it could be that the commonly found firm-size effect stems from an aggregation phenomenon. If each firm has an equal probability of training any one of its workers irrespective of firm size, large firms are more likely to train someone in any given period simply because they have more workers.

7 The output growth variable was created using the Census of Manufacturers data. On the basis of change in shipments over the period 1980 to 1989 , plants were ranked into three equal sized groups. These groups correspond to negative or slight growth, moderate growth, and rapid growth. The moderate and rapid growth groups were combined for the purposes of this analysis, as tests indicated that there was no significant difference between the coefficients on these two groups in the probit regression results. 
Size is measured for both the plant and its owning enterprise. The scale of the plant is measured by the number of production and non-production workers employed by the plant and by its owning enterprise. ${ }^{8}$ In order to purge the size variable of the effects of recent growth, which is captured by a separate variable, plant size is measured as of 1980. A binary variable is created, equaling zero for small plants (less than 100 employees) and one for medium to large plants (more than 100 employees). To separate the effects of enterprise from establishment size, establishment employment is subtracted from enterprise employment, creating an enterprise employment variable. Three binary variables are created to capture variations in the amount of employment in the enterprise that is outside of the particular plant in question. The three variables are: the case where the owning enterprise is the same as the size of the establishment-a stand-alone plant (small)-and residual enterprise sizes of 1 to 999 employees (medium) and 1000 or more employees (large). ${ }^{10}$

Finally, the fact that Canada's economy is regionally based necessitates the inclusion of a set of binary variables that control for regional differences. The five regions are the Maritimes, Quebec, Ontario, the Prairies, and British Columbia.

The observations used in the probit regression are establishment- and shipment-weighted. If no weights are used, the regression results are representative of the panel used for the survey-a panel which over-represents large plants in particular. Weighting by establishment provides a picture that is more representative of the average manufacturing plant in the population as a whole. ${ }^{9}$ Weighting by shipments provides a systematic method of examining the extent to which the results differ in large and small plants. In the discussion that ensues, emphasis will be placed on the establishment-weighted results with brief mention being made of differences that are generated when large plants are given more importance.

\subsection{Empirical Results: Incidence of Training}

Table 4.1 presents the results of the probit regression models for the probability of the plant offering training. The dependent variable is 1 (the plant engages in formal training) or 0 (the plant does not). ${ }^{10}$ Since each of the explanatory variables takes a value of either zero or one, the coefficient attached to the explanatory variable is the effect on the probability of training when that variable is equal to one.

The results of the establishment-weighted regression indicate training is an important part of a technology strategy. Technology use itself is one of the most important determinants of whether or not a plant will train its employees. The effects of technology use are measured against an

8 The size of the owning enterprise is defined as the total employment of all plants in manufacturing owned by the enterprise that controls the plant.

9 Appendix A compares the unweighted results of the panel to both establishment- and shipment-weighted results. The shipment-weighted results are generally similar to the unweighted panel results since the panel over-represents large plants. The shipment-weighted results, however, provide a more systematic method than the unweighted results of considering the extent to which the regression results differ in the large firm population from the results for the population as a whole.

10 The probit typically estimates the probability of the dependent variable being zero. Consequently, for ease of interpretation, the signs on the coefficients have been reversed. 
omitted variable of no advanced technology use. The results show plants using two to five technologies are more likely to train than plants using none. Plants using more than five advanced technologies are the most likely to train their workers. Plants that have difficulty in hiring personnel to work with those technologies are also more likely to train. Holding other factors constant, plants experiencing difficulties in this area are more likely to engage in training.

The decision to train is also an integral part of the strategies of successful establishments; holding all else constant, characteristics associated with success lead to an increased probability of training. Engaging in R\&D, and to a lesser degree, operating in an innovative industry, are factors that increase the probability of training. Both are indicators of management's willingness to learn and adapt and, as such, should be positively correlated with training. The effect of growth in manufacturing sales on the probability of training is also unambiguous. Plants that experienced moderate to rapid growth are more likely to offer training than those with only negative or slight growth.

The effects of diversification on training are measured against an omitted variable representing operation in one industry. The results indicate that more diversified enterprises are more likely to engage in training than single industry producers, likely pointing to the existence of spill-over benefits to training.

The age and ownership of the plant also impact on the probability of training. Plants that were in existence before 1970 are more likely to train than younger plants. ${ }^{11}$ These plants have well established structures and have the benefit of experience to develop effective training programs. Foreign-owned plants are also more likely to train, but the coefficient attached to this variable is one of the few that is not significant at even the 10 percent level in the establishment-weighted results, although it is significant in the shipment-weighted model.

Strong regional effects are also seen in the model. The omitted variable here is the Atlantic region. Once other factors are held constant, plants in each of the other regions except Quebec are less likely to train than plants in Atlantic Canada.

The effects of establishment and enterprise size are both measured relative to the stand-alone plant. The estimated coefficients indicate a negative relationship between training and indicators of plant and firm size. This result is contrary to many previous studies (Bartel, 1989), though it should be recognized that other studies have not been able to measure technology with the same detail.

11 Entrants in the survey occur mainly in the 1970s and, therefore, were relatively mature. It is possible that younger entrants might have fared differently. 
Table 4.2

The Factors that Influence a Plant's Decision to Train

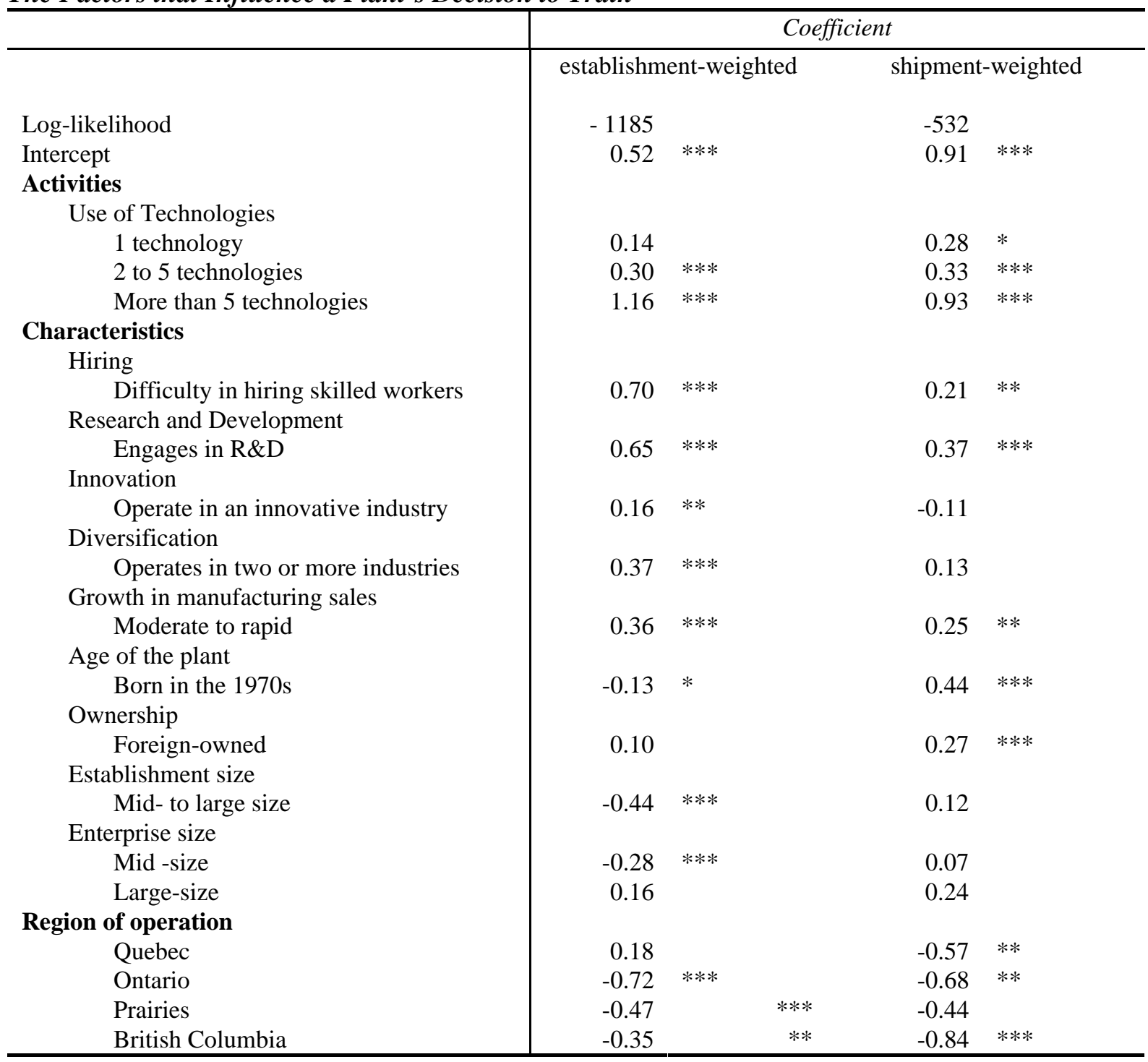

*** Significant at the 1 percent level, ** significant at the 5 percent level, * significant at the 10 percent level.

To explore this issue, training is regressed on enterprise size, technology use and interaction terms involving technology use and size (Table 4.3). When these interaction effects are factored in, training has a positive relationship with both the number of technologies in use and the size of the enterprise. The interaction effects are negative, indicating the marginal effects of size are less for technology-using plants. Technology-using plants tend to do more training, and perhaps as a consequence, the effects of size on training are less in technology-using plants. 
Table 4.3

Interaction Effects between Technology, Training and Enterprise Size (Establishment-weighted)

\begin{tabular}{|c|c|c|}
\hline & \multicolumn{2}{|l|}{ Coefficient } \\
\hline & \multicolumn{2}{|c|}{ establishment-weighted } \\
\hline Log-likelihood & -1352 & \\
\hline Intercept & 0.64 & $* * *$ \\
\hline Enterprise size & & \\
\hline Mid-size & 0.32 & $* * *$ \\
\hline Large-size & 0.62 & $* * *$ \\
\hline Technology use & & \\
\hline One technology & 0.67 & $* * *$ \\
\hline Two to five technologies & 0.97 & *** \\
\hline More than five technologies & 1.65 & *** \\
\hline Interaction Variables & & \\
\hline Mid-size enterprise, one technology & -0.40 & ** \\
\hline Mid-size enterprise, two to five technologies & -0.80 & $* * *$ \\
\hline Mid-size enterprise, more than five technologies & -0.05 & \\
\hline Large-size enterprise, one technology & -0.51 & * \\
\hline Large-size enterprise, two to five technologies & -0.25 & \\
\hline Large-size enterprise, more than five technologies & -0.09 & \\
\hline
\end{tabular}

*** Significant at the 1 percent level, ** significant at the 5 percent level, * significant at the 10 percent level.

The interaction terms are sufficiently correlated with the independent variables in the broader model that they are not included in the main results reported in Table 4.2.

The effect of size can also be inferred from the differences in the coefficients of the establishment- and the shipment-weighted estimates of the training regression in Table 4.2. These differences reflect the extent to which the effect of these variables varies between large and small plants. Large plants are already doing more training than small plants and the marginal effect of some variables has less effect. On this basis, large plants are less likely to train just because they are in an innovative industry, because they are diversified, because they use technologies, because they are growing, or because they have difficulty in hiring. They are more likely to train if they are younger or if they are foreign-owned. Foreign-owned plants tend to be larger and the coefficient attached to foreign-ownership increases when their size is factored in via shipment-weighting. 


\subsection{Technology and Type of Training}

\subsection{Determinants of The Type of Training}

A manufacturing firm's strategy does not end with the decision to train. It must decide where the formal training will take place. This paper distinguishes between formal training taking place on and off the plant floor and explores the various factors influencing this decision.

The location of training done by a plant is available from the 1989 Survey of Manufacturing Technology, where plants were asked whether they primarily performed training within the plant, elsewhere in the firm, or through the purchase of training courses in public or private institutes. More than half $(63 \%)$ of both large and small plants that train do so within the plant. By way of contrast, 37 percent of plants train elsewhere (Table 5.1).

Table 5.1

Location of Training for Plants that Train Workers

\begin{tabular}{lcc}
\hline & \multicolumn{2}{c}{ Percent of establishments } \\
\cline { 2 - 3 } & establishment-weighted & shipment-weighted \\
\hline Training purchased outside the firm & 19 & 29 \\
Training provided within the plant & 63 & 55 \\
Training provided elsewhere in the firm & 18 & 16 \\
\hline
\end{tabular}

Source: The Survey of Manufacturing Technology (1989).

\subsection{Why Does the Location of Training Matter?}

Training can be aimed at upgrading two types of skills. The first are generic skills that are easily transferred across firms. Skill development in this area can suffer from externality problems. Workers, once they receive training, can move to other firms who will readily compensate them for their skills without having had to bear the training costs. Firms that know they will lose some of their investment in general training because of this, may be less likely to make these investments (Mincer, 1989 and Simpson, 1984). Although they may still have an incentive to invest, their investments will be less than is optimal for society. These type of programs are, therefore, generally supported with public funds. Vocational training programs are one example of this type of publiclysupported training program.

This externality problem in training is akin to the externality problem sometimes associated with research and development. Since firms are not going to make investments in research that produces generic ideas that are easily copied by others, intellectual property rights such as patents are granted. These rights protect innovations and provide the appropriate incentive to invest in research and development. While the existence of externalities creates a public policy problem, some have questioned whether the problem is very widespread. They have noted that the externality problem in research and development may not be very important, since ideas and knowledge are often highly 
specific to firms. Mowery and Rosenberg (1989) have stressed that much of the knowledge that is important to the innovative process is "tacit". It is not easily codified or communicated and depends on innate skills that are specific to particular firms. As such, appropriability exists without the protection of legislative statute because the act of turning that knowledge into a new product or process is difficult and costly and is not readily transferable.

Training also creates tacit knowledge. This involves skills that allow employees to make things work in the context of a specific organization. Workers with tacit knowledge do not have the same value to other firms and are, therefore, less likely to be hired for that knowledge alone. Investments by the firm in tacit or firm-specific knowledge are less likely to be lost and, therefore, are more likely to be provided in socially optimal amounts by firms responding to private incentives.

Training that is plant-specific is more likely to be done on the plant floor, where workers learn how processes work. For example, knowledge of a new metallurgical process is often limited to the firm that pioneered the process. Skills related to that process are generally only imparted within the plant, where the knowledge about the process resides. On the other hand, training that is generic in nature is more likely to be done off the plant floor-either elsewhere in the firm or completely outside the firm. Thus, plants that train mainly on the plant floor are likely to be imparting plant-specific skills; those training off the plant floor are more likely to be imparting generic skills. Therefore, modelling the determinants of location permits us to examine the determinants of the type of training. In order to do so, plants are grouped into those primarily training within the plant and those doing so elsewhere-either elsewhere in the firm or outside the firm. The dependant variable is a zero-one variable, where one stands for training primarily done within the plant.

\subsection{A Model of the Location of Training}

In order to understand the extent to which the training associated with advanced technologies is generic or firm-specific, this section investigates the determinants of the location of training. The location of training is postulated here to be related to the basic nature of the training being imparted.

Firms will find it necessary to train when the skill requirements of their workers change and when they cannot easily hire appropriately qualified employees. Firms will be less likely to hire appropriately qualified employees when a) their skill requirements are highly firm- or plantspecific, or b) the skills that they require are very sophisticated and, consequently, rare.

Specific skills are those that are uniquely adopted to the production process of a particular firm. They do not require a high knowledge or competency per se. Sophisticated skills, however, are those that $d o$ require high levels of knowledge and competencies. Sophistication is a characteristic both of generic and plant-specific skills. Firms will combine both generic and specific skills in different proportions.

An example of a specific skill is the knowledge associated with the utilization of an automated guided motor vehicle (AGV) system on a plant floor. Training in this case allows employees to 
make the AGV work in the particular confines of the plant. On the other hand, sophisticated nonspecific skills are required for the artificial intelligence/expert system, an integration and control technology, that controls AGVs and other computer-based technologies in the plant. These types of technologies rely on highly complex and sophisticated logical statements that are generic to most applications. In order to be able to accommodate the introduction of new technologies that are controlled by this integration technology, users must be able to understand how the logic of the technology works, regardless of the specific application. Consequently, users require a more general skill set and generic training for the application of this technology. Finally, an example of a sophisticated plant-specific skill is provided by materials requirement planning technologies. These technologies require specific knowledge of the plant's inputs, as well as some general knowledge of how to adapt the system as processes, prices, and products change.

A firm can typically impart plant specific or generic skills by training either on the plant floor or off the plant floor. It is postulated here that if a firm's skill requirements are primarily plant-specific, regardless of the degree of sophistication, it will be more likely to train on the plant floor; if its skill requirements are primarily for sophisticated skills that are relatively non-plant-specific, it will be more likely to train off the plant floor. There will be a degree of plant-specificity to all desired training, and a degree of sophistication in order for training to be required; however, it is the dominance of specificity versus non-specificity that is critical to determining where training is performed.

\subsubsection{Plant Specific Knowledge}

There are two factors imparting the specificity, and thus the location, of the desired training. The first is the specificity of the work activity itself, that is, the extent to which the work involves tacit knowledge. In the example cited above, the use of the AGV technology constituted an activity specific to the plant floor. The second factor that determines the specificity of the desired training is the degree of tacit knowledge within the firm. Leading firms are those which have found a method of succeeding that others cannot emulate. By definition, they possess special knowledge. Followers are those which adopt a strategy of employing existing or generic knowledge. Therefore, leading-edge firms should be expected to do more training that develops plant-specific skills.

\subsubsection{Sophisticated Non-specific Knowledge}

In addition to the specificity of the skill set being imparted by training, there is a second elementthe degree of sophistication of the technology-that should also affect the location of training. The use of each technology will require both specific and generic skills. If the sophisticated skills are plant-specific, it will have to be done on the plant floor. To some extent, plant-specificity will exist in all training. However, in many cases, the degree of specificity will be minor. For example, artificial intelligence/expert systems are highly sophisticated systems that need to be adapted to specific environments but which primarily require generic skills to operate them. 
The more sophisticated the technology, the more likely it is that the firm will have to look outside itself for expertise in utilizing and exploiting those technologies. While firms could bring in external specialists to train on their shop floor, several factors are likely to favor external training for sophisticated tasks.

First, it is usually the case that the more sophisticated the desired training, the greater the specialization of function and the smaller the range of workers within any establishment to which the training will apply. Therefore, the costs of bringing a specialist, or having a training specialist on staff can only be spread over a small number of workers. Furthermore, the more sophisticated the required training, the more likely it is to require specialized facilities-either in the way of a classroom or in the way of specialized equipment. These facilities will normally be located elsewhere for reasons of agglomeration economies. Consequently, it will be more cost effective to send those employees who require training on sophisticated technologies to locations outside the plant for that training. In outside training, these costs are spread across many workers, often from different firms, who also share the training facilities.

A second related point is that when only a small number of employees require training, then training on the plant floor will be more disruptive to the production process. If the introduction of a new technology requires that only a small number of employees on the plant floor undergo training, then training them on the plant floor will disrupt the work of many other workers who are not being trained.

Third, the more sophisticated are the technologies in use, the greater the benefits the firm can derive by sending their employees for external training. External training courses offer an opportunity for employees to develop contacts with specialists in their field. Informal communication networks, even across competitors, have been found to be a critical source of information. "Individual employees provide information to colleagues from other firms with the expectation of receiving valuable information in return, either immediately, or in the future" (Schrader, 1990). The more sophisticated the technologies, the more firms can expect to gain by developing networks with others utilizing the same technologies.

There is another reason that sophisticated technologies will require external training. Sophistication may itself involve higher levels of generic knowledge. It is certainly the case that some sophisticated processes involve the type of generic knowledge that is only found in universities. Firms have long developed partnerships with universities to produce the skills that they need. Nelson and Rosenberg (1994) describe how US engineering schools were a fortuitous response of the university system to the needs of the industrial system for generic skills associated with an increasingly complex set of technologies.

\subsection{Determinants of Training}

\subsubsection{Technologies}


In order to allow for differences in sophistication across technologies, the two sets of technology adoption variables that measure incidence and pattern of use are employed. Incidence is measured by the number of advanced technologies that are used. Once the degree of tacit knowledge within the firm is accounted for, plants using more technologies are hypothesized to do more training off the plant floor because of their sophistication. Sophistication here primarily derives from the need to integrate and control different functions as more and more technologies are utilized. In a second probit regression, the effect of the pattern of technology use is measured by including six separate variables representing technology use for each of the six functional groups. These variables equal one if at least one technology is used from a particular functional group, and zero otherwise. The sign of the coefficients attached to each indicates whether use of technologies in each of these groups is associated primarily with plant-specific skills or with sophisticated non-specific skills.

\subsubsection{Other Plant Characteristics}

Since dynamic leading-edge firms are hypothesized to require plant-specific training, several different attributes are included to measure whether the firm is an industry knowledge leader. One of the prime factors in success is an innovation and technology driven strategy (Baldwin et al., 1994). Plants that report a research and development unit within the organization are more likely to develop entirely new products and processes; plants that report they modify, instead of just adopting, the technologies of others have leading-edge capabilities. Both of these categories are included as explanatory variables in the probit regression.

There are other characteristics likely to be correlated with leading-edge knowledge intensive firms. Firms that operate successfully in multiple product markets succeed not just because they offer one superior product, but because they have developed a set of superior competencies that afford success in multiple product markets. Firms that are older, ceteris paribus, have survived by building and maintaining skills exceeding those of their competitors. Foreign-owned firms, which have succeeded not just in their own domestic markets but have crossed geographical, political, and cultural borders to succeed in a foreign country, embody special knowledge. Growing firms are those which have managed to succeed in an economy where knowledge is increasingly important and, therefore, might be expected to emphasize internal skills. Therefore, the same measures of diversification, age, foreign-ownership, and growth that were included in the training equation are used here in the training-location regression.

Finally, the size of the plant and of the owning firm are also included as explanatory variables. Size represents two factors, each with opposing effects on the location of training. On the one hand, size represents competence and age. To the extent that this competence depends on knowledge that is not easily replicated, size will be positively correlated with in-plant training. On other hand, size may represent sophistication. Larger plants tend to use more sophisticated technologies than smaller plants. Because of this, larger plants will have a tendency to do more training elsewhere than on the plant floor. Whether the sign of the coefficient is positive or negative will depend upon which of the two effects dominates. 
It should be recognized that this multiplicity of effects is true for all the regressors. For example, plants with research and development are both sophisticated and engaged in activities that require plant-specific knowledge. And it is no doubt true that almost all plants will invest in both generic and plant-specific skills. However, the dependent variable is derived from the question that asked plant managers where most training was done. Therefore, the sign of the regressor in the probit regression indicates whether the predominant form of training involves plant-specific or more generic and sophisticated types of knowledge.

\subsection{Empirical Results}

Both establishment- and shipment-weighted results of the regression model for the probability of training off the plant floor are presented in Table 5.2. The coefficients associated with the explanatory variables have the same interpretation as in the model of training reported above; however, now the dependent variable is 1 if a plant trains mainly off the plant floor and 0 if it trains mainly on the plant floor. A plant that trains mainly off the plant floor may do so elsewhere in the firm or through purchased training courses. As this model uses only the data on plants that engage in training, the coefficients on the variables confer exactly equal and opposite effects on the probability of training on the plant floor. Thus, a positive sign on a coefficient indicates the effect on the probability of training off the plant floor when that variable is equal to one, while a negative coefficient is the effect on the probability of training on the plant floor when that variable is equal to one. In all cases, the omitted variables remain the same as in the model of training presented above.

When the number of technologies are used as regressors (Table 5.2, column 1), the signs of the coefficients are positive and significant. When a plant uses more technologies, it is more likely to do training off the plant floor. Sophistication, then, is equated with the number of technologies that are utilized by the plant. The use of technologies by itself stimulates firms to offer more high risk training, that is, training in order to impart sophisticated, generic skills.

The coefficients attached to the technology use by functional category (Table 5.2, column 2) reveal which of these require more sophisticated generic skills and which are more closely associated with firm-specific skills. Automated materials handling systems, design and engineering, and manufacturing information systems technologies are all highly specific to the plant and, consequently, are all more likely to be related to in-house training. This is confirmed by the negative coefficients associated with each of these technologies, two of which are significant.

Conversely, inspection and communications technologies are more general, off-the-shelf type products. Communication technologies are relatively generic. They are not specific to any part of the production process. Thus, users of communication technologies would be more likely to purchase training. This is supported by a significant positive coefficient on the communications category, and also by evidence provided by the marketplace, in the growth and proliferation of firms whose main purpose is to develop training programs for communications technology. 
Fabrication and assembly as well as integration and control technologies are sophisticated technologies that also have positive coefficients. Training here is accomplished mainly off the plant floor, perhaps by the supplier who has specialized facilities for training on the new equipment. Given the sophistication of these technologies, the plant is unlikely to have significant expertise in training for these technologies on the plant floor. The cost associated with bringing a specialist in to the plant to train a small number of workers, and the potential benefits of networking with others utilizing the technologies, lead to more off-site training.

Variables other than those dealing with the use of technologies are also significantly related to the location of training. Plants experiencing difficulty in hiring skilled workers are more likely to train on the plant floor. This is consistent with the argument that the demand for workers with plant-specific skill sets cannot be met through external hiring. Alternatively, it is likely that if more general skills are available through purchased training programs outside the firm, prospective employees would have obtained this training prior to seeking employment with the firm.

The results also confirm training on the plant floor, which is associated with the development of firm-specific skills, is related to whether a firm is at the leading-edge of the industry. Plants with access to their firm's research and development, that modify their advanced technologies to improve output, that belong to diversified parents, and/or mature, are more likely to train on the plant floor.

The size and scale variables show the importance of sophistication and economies of scale and task specialization in the location of training. Again, the omitted variable for plant size is less than 100 employees or a stand alone plant for the enterprise variable. Small plants are more likely to train on the plant floor. If the plant is large, training is more likely to take place elsewhere in the firm, or outside the firm through purchased training courses. 
Table 5.2

The Factors that Influence the Type of Training-for Training Off the Plant Floor

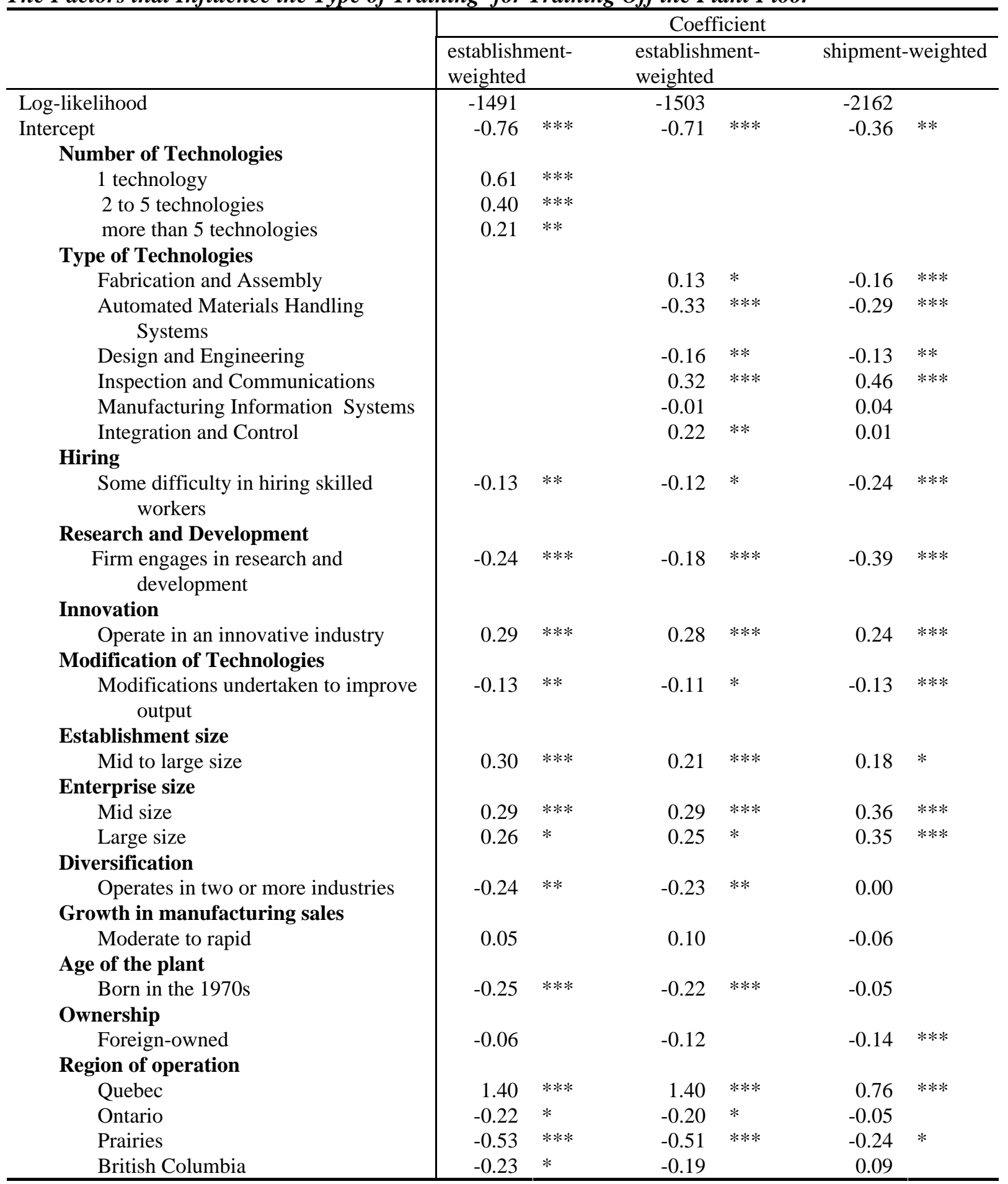

*** Significant at the 1 percent level, ** significant at the 5 percent level, * significant at the 10 percent level.

When the shipment-weighted probit results (Table 5.2, column 3) are compared to the establishment-weighted results (Table 5.2, column 2), the story is much the same, with the following exceptions. The coefficient attached to fabrication and assembly becomes negative, 
thereby indicating that larger plants tend to have more specific skills attached to this technology than smaller plants. The coefficient attached to R\&D increases, thereby indicating that larger plants with $R \& D$ tend to have even more plant-specific skills than smaller R\&D performers. Plant age is no longer negative and significant, thereby indicating that the newer large plants are more likely to require more generic skills. Finally, the coefficient attached to foreign ownership becomes significant.

\subsection{Technology and Training Costs}

The first two sections of this paper investigate the relationship between the use of advanced technologies and the development of skills. This is done by both examining the extent to which technology users have experienced a need for increased skills and the extent to which they have implemented training programs to meet these needs. The importance of these training programs depends, in one sense, on their intensity; intensity is measured here by costliness. This section provides evidence that training costs associated with advanced technology use increased with the adoption of new technologies.

Table 6.1

Impact of Technologically Advanced Equipment and Software on Education and Training Costs

\begin{tabular}{lccccccrr}
\hline & \multicolumn{2}{c}{$\begin{array}{r}\text { Fabrication and } \\
\text { Assembly }\end{array}$} & $\begin{array}{c}\text { Automated Material } \\
\text { Handling Systems }\end{array}$ & \multicolumn{2}{c}{$\begin{array}{r}\text { Design and } \\
\text { Engineering }\end{array}$} & $\begin{array}{r}\text { Inspection and } \\
\text { Communications }\end{array}$ \\
\cline { 2 - 9 } & $\mathrm{S}$ & $\mathrm{E}$ & $\mathrm{S}$ & $\mathrm{E}$ & $\mathrm{S}$ & $\mathrm{E}$ & $\mathrm{S}$ & $\mathrm{E}$ \\
\hline Increased significantly & 23 & 15 & 15 & 4 & 20 & 20 & 20 & 10 \\
Increased moderately & 40 & 15 & 24 & 5 & 35 & 16 & 29 & 12 \\
Increased marginally & 14 & 10 & 16 & 5 & 24 & 13 & 19 & 11 \\
No change & 12 & 8 & 32 & 11 & 12 & 9 & 12 & 9 \\
Decreased & 1 & 3 & 0 & 0 & 0 & 2 & 0 & 0 \\
\hline
\end{tabular}

Source: The Survey of Innovation and Advanced Technology (1993) S=shipment weighted, E=establishment-weighted.

The impact of technology adoption on the intensity of training was investigated on the 1993 Survey of Innovation and Advanced Technology by asking manufacturing plants what impact the adoption of technology had on their education and training costs. The responses are available by area of advanced technology use-for fabrication and assembly, materials handling, design and engineering, and inspection and communications. The responses, both shipment-weighted and establishment-weighted, confirm the conclusions drawn from the multivariate analysis (Table 6.1). Technology has a significant impact on the investment in human capital that manufacturing plants are making. Between two-thirds and three-quarters of technology-using plants (shipmentweighted) reported that the adoption of that technology increased their education and training costs in each of the different functional areas (see Table 6.1). One-third of plants that reported an increase in costs associated with technology use respond that technology use increased training 
costs significantly. As was the case with the incidence of skill change, the shipment-weighted estimates on skill upgrading are greater than the establishment-weighted estimates. It is the largest plants that generally are the most sophisticated technology users and that incur the greatest increases in their training costs as a result of technology adoption.

\subsection{Conclusion}

Technological progression has arguably been one of the most dramatic features of recent changes in the work and leisure environment. Robots and laser technologies are becoming common place in surgical rooms. Virtual reality environments and three dimensional audio-visual shows are but a few examples of the impacts of the technological revolution on the recreational environment. Entire manufacturing plants are controlled by computers-from inventory planning, storage retrieval and production, to quality testing and receiving and processing customer orders.

These technological changes have meant radical changes in the nature of work. Previous research (Baldwin, Diverty, and Johnson, 1995) has demonstrated that technology adoption is associated with higher wages, which are an indication of more skilled workers. Not only do plants that adopt advanced technologies pay higher wages, they also have had a higher rate of wage growth in the 1980s. Therefore, the wage differential and by inference, the skill differential between firms that adopt advanced technologies and those that do not has widened.

The analysis here confirms that technology adoption creates a need for higher skill levels and stimulates firms to train. Three separate, but complementary, pieces of evidence have been adduced to show that recent technological change has generally been skill-enhancing. First, it has been demonstrated that plant managers generally find that skill requirements have increased as a result of the adoption of advanced technologies. Second, plants with advanced technologies are more likely to have formal training programs, even when other factors are taken into account. Third, the increased skill requirements have led to increased training costs. These three pieces of evidence, along with the previous study on wage differentials between plants with and without advanced technologies, strongly suggests that advanced technology implementation in the Canadian manufacturing industry has had an important skill-enhancing effect. The implication, then, is that technology use in manufacturing plants is associated with higher quality jobs-jobs in which workers are continually challenged with more sophisticated tasks, and where they are supported by the firm, through training, in successfully completing these new tasks.

This paper identifies various factors that lead firms to train. Foremost among these is the use of advanced manufacturing technologies, and problems in hiring skilled employees to work with new technologies. Characteristics that are associated with past success, and are indicative of superior abilities to adapt and learn, are also associated with training. Consequently, firms that are most likely to train are those that perform $R \& D$, are innovative, diversified, mature, foreign owned, and most directly of all, have achieved strong growth.

It is, therefore, significant that many of the same variables-number of technologies used, the possession of R\&D facilities, diversification, ownership, and hiring difficulties-are all associated with both more training and a greater likelihood of training on the plant floor. The skills being 
developed by the training that is provided by plants either are highly plant-specific, or the incentives to train lead manufacturing firms to invest primarily in this type of training.

The paper has also outlined the differences between large and small plants both with regards to technology use and the extent to which the adoption of technology is associated with increased training and skill requirements. While skills are generally enhanced and training costs are increased by the adoption of new technologies, these effects are felt particularly in larger plants. Larger plants tend to use more technologies, to integrate more technologies together, and to use more sophisticated technologies. These use patterns are associated with greater skill and training requirements. The training for these sophisticated skills is done primarily off the plant floor, thereby suggesting that much of the sophisticated training these plants employ is aimed at generic skills. Firm-specific training that is done primarily on the plant floor is a characteristic not of large plants, but of growing leading-edge plants who often have proprietary knowledge. This knowledge can only be taught within the confines of the plant, close to the production process. Leading-edge plants are not necessarily large; they engage in research and development, solve technological problems and are growing rapidly.

Several policy implications arise from this analysis. Technology using firms tend to demand greater skills, do more training, and invest more in human capital. Accordingly, they tend to offer better jobs and pay higher wages. This confirms the complementarity of technology and human resource policies suggested by Baldwin and Johnson (1995a). That study, using data from the Growing Small and Medium-Size Firm Survey (1992), links innovation to a broad range of human resource strategies being pursued by the firm. Specifically, firms that recognize the importance of labour skills, that focus on developing innovative employee compensation plans, that stress quality and total quality management and implement training programs are more likely to be innovative.

The second important point is that advanced technology use stimulates firms to engage in both plant-specific training as well as generic training to develop sophisticated skills. While leadingedge firms tend to focus on plant-specific training, the need for sophisticated generic skills leads in many instances to generic training despite the existence of an externality problem with the latter. The desire for sophisticated generic skills in large plants that use many technologies is sufficient to overcome the likelihood that they risk the loss of these investments if their employees leave for other firms. On the other hand, plants with fewer advanced technologies are less likely to engage in developing the type of generic skills that are associated with off-theplant-floor training. The difference between large and small plants in this regard is probably tied to the differences in the worker turnover rates of large and small plants. With lower turnover rates, larger plants are less likely to lose workers and, therefore, have a greater tendency to invest in the generic skills that are required for sophisticated advanced technologies. 


\section{Appendix A}

Table A.1

The Factors that Influence a Plant's Decision to Train



*** Significant at the 1 percent level, ** significant at the 5 percent level, * significant at the 10 percent level. 
Table A.2

The Factors that Influence the Type of Training (Training Done off the Plant Floor)

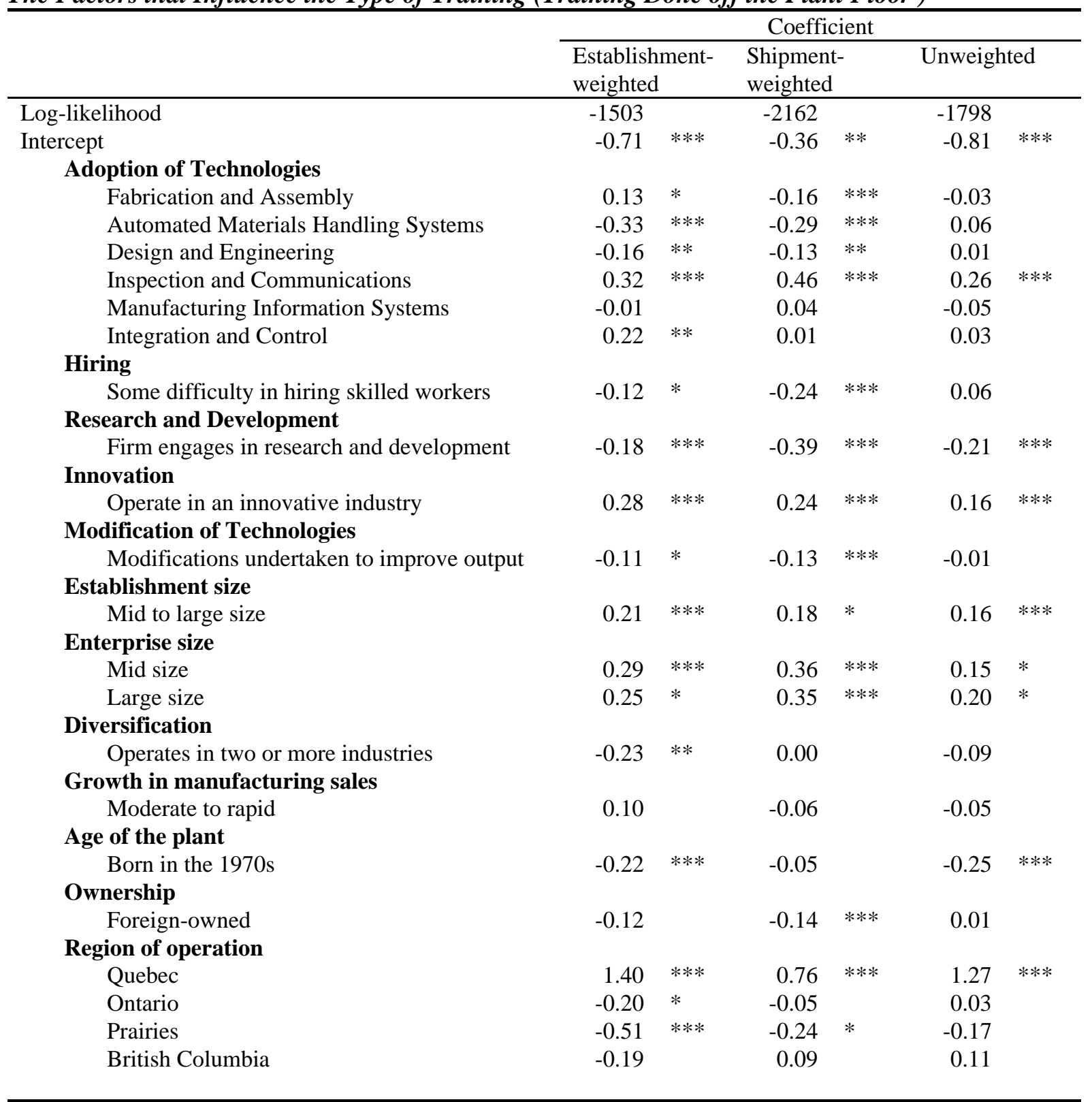

\footnotetext{
$* * *$ Significant at the 1 percent level, ** significant at the 5 percent level, * significant at the 10 percent level.
} 


\section{References}

Baldwin, J. R. and J. Johnson. 1995a. "Human Capital Development and Innovation: The Case of Training in Small and Medium Sized-Firms". Research Paper Series No. 74. Analytical Studies Division. Statistics Canada.

Baldwin, J. R. and J. Johnson. 1995b. "Human Capital Development and Innovation: A Sectoral Analysis". in P. Howitt (ed.) The Implications of Knowledge Based Growth for Micro-economic Policies.

forthcoming.

Baldwin, J.R. and D. Sabourin. 1995. Technology Adoption in Canadian Manufacturing.

Catalogue No. 88-512 Occasional. Ottawa: Statistics Canada.

Baldwin, John R., William Chandler, Can Le and Tom Papailiadis. 1994. Strategies for Success. Catalogue No. 61-523E. Ottawa: Statistics Canada.

Bartel A. 1989. "Formal Employee Training Programs and Their Impact on Labour Productivity: Evidence from a Human Resources Survey”. Working Paper No. 3026. National Bureau of Economic Research.

Bartel A. and F. Lichtenburg. 1987. "The Comparative Advantage of Educated Workers in Implementing New Technology". The Review of Economics and Statistics. Vol. 69, pp.1-11.

Betcherman, G. and K. McMullen. 1986. Working with Technology. Economic Council of Canada. Ottawa: Supply and Services Canada.

Betcherman, G. 1994. "Inside the Black Box: Human Resource Management and the Labour Market," unpublished.

Bylinsky, G. 1994. “The Digital Factory”. Fortune. November. pp. 92-110.

Caves, R.E. 1982. Multinational Enterprise and Economic Analysis. Cambridge: Cambridge University Press.

Doeringer P. and M. Piore. 1971. International Labour Markets and Manpower Analysis. Lexington: D. C. Heath.

Gunderson, M. 1974. “ The Case for Government-Supported Training Programs”. Relations Industrielles. Vol. 29. pp. 709-725.

Hashimoto, M. 1979. "Bonus Payments, On-the-job Training, and Life-Time Employment in Japan”. Journal of Political Economy.Vol. 87. pp. 1086-1104. 
Keefe. J. 1991. "Numerically Controlled Machine Tools and Worker Skills". Industrial and Labour Relations Review. Vol.44, No.3. pp. 503-519.

Matzner, E. and R. Schettkat and M. Wagner. 1990. "Labour Market Effects of New Technology". Futures. September. pp. 687-709.

Mincer, J. 1989 "Human Capital Responses to Technological Change in the Labour Market". Working Paper No. 3207. National Bureau of Economic Research.

Mowery, D.C. and R.N. Rosenburg. 1989. Technology and the Pursuit of Economic Growth. Cambridge: Cambridge University Press.

Rosenberg R.N and N. Nelson. 1994. "American Universities and Technical Advance in Industry”. Research Policy. Vol 23. pp. 323-348.

Organization for Economic Cooperation and Development. 1991. "Enterprise Related Training". In Employment Outlook. Paris: OECD. pp. 135-175.

Robson, M. and J. Towsend and K. Pavitt. 1988. "Sectoral Patterns of Production and Use of Innovations in the UK: 1945 to 1983". Research Policy. Vol.7, No.1. pp. 1-14.

Schrader. S. 1991. "Informal Technology Transfer Between Firms: Cooperation Through Information Trading”. Research Policy. Vol 20. pp. 153-170.

Simpson, W. 1984. “An Econometric Analysis of Industrial Training in Canada”. The Journal of Human Resources. Vol. 19, pp. 435-51. 